\title{
Energy-Dependent Collision-Induced Dissociation of Lithiated Polytetrahydrofuran: Effect of the Size on the Fragmentation Properties
}

\author{
Ákos Kuki, a Lajos Nagy, ${ }^{a}$ Antony Memboeuf, bászló Drahos, ${ }^{\text {b }}$ \\ Károly Vékey, ${ }^{b}$ Miklós Zsuga, a and Sándor Kéki ${ }^{a}$ \\ ${ }^{a}$ Department of Applied Chemistry, University of Debrecen, Debrecen, Hungary \\ b Institute of Structural Chemistry, Chemical Research Center, Hungarian Academy of Sciences, Budapest, \\ Hungary
}

The fragmentation properties of singly and doubly lithiated polytetrahydrofuran (PTHF) were studied using energy-dependent collision-induced dissociation. The product ion spectrum of $[\mathrm{PTHF}+\mathrm{Li}]^{+}$showed the formation of three different series corresponding to product ions with hydroxyl, aldehyde and vinyl end-groups. Interestingly, besides these series, two additional, non-lithiated product ions $\mathrm{C}_{4} \mathrm{H}_{9} \mathrm{O}^{+}$and $\mathrm{C}_{4} \mathrm{H}_{7}^{+}$were identified in the MS/MS spectra. The MS/MS of the doubly lithiated PTHF $\left([\mathrm{PTHF}+2 \mathrm{Li}]^{2+}\right)$ with a number of repeat units ranging from 8 to 27 showed the formation of product ions similar to those of the singly lithiated series, however, doubly lithiated product ions and product ions formed by the loss of one $\mathrm{Li}^{+}$-ion from the precursor ion also appeared with significant abundances. Analysis of the breakdown curves for the singly and doubly charged PTHF indicated that the series A ions are formed most probably together with the series B ions, while members of the series $C$ ions appeared at significantly higher collision energies. The fragmentation properties of [PTHF + $\mathrm{Li}]^{+}$and $[\mathrm{PTHF}+2 \mathrm{Li}]^{2+}$ were also interpreted using the survival yield method. It was found that the collision energy/voltage necessary to obtain $50 \%$ fragmentation $\left(\mathrm{CV}_{50}\right)$ was dependent linearly on the number of the repeat units, i.e., on the size, or the number of degrees of freedom (DOF). (J Am Soc Mass Spectrom 2010, 21, 1753-1761) (c) 2010 American Society for Mass Spectrometry

$\mathrm{P}$ olytetrahydrofuran (PTHF), also named poly(tetramethylene oxides) (PTMO) or poly(tetramethylene glycols) (PTMG), are widely used as the soft segments in many polyester- (e.g., Hytrel), polyurethane- (e.g., Lycra), and polyamide- (e.g., Vestamid) based thermoplastic elastomers [1]. PTHFs are also important constituents of many bioresistant and biocompatible thermoplastic polyurethane elastomers targeted at various biomedical applications [2-5]. As the application of PTHFs is expected to increase further in the future, it is important to have an analytical method suitable for the unambiguous determination of the structure and the molecular weight of PTHFs even in complex mixtures. Mass spectrometry combined with soft ionization methods, such as matrix-assisted laser desorption/ionization (MALDI) [6, 7] or electrospray ionization (ESI) [8], can satisfy these requirements. MALDI-MS and ESI-MS allow the determination of the mass of the repeat unit and the end-groups of polymers. Furthermore, if tandem MS (MS/MS) is applied, structural information on

Address reprint requests to Dr. S. Kéki, Department of Applied Chemistry, University of Debrecen, Egyetem ter 1, Debrecen, Hungary. E-mail: keki@ tigris.unideb.hu polymers can also be obtained. The typical molecular weights of PTHFs used for making thermoplastic elastomeric materials for different applications fall into the range of $600-2000 \mathrm{~g} / \mathrm{mol}$ [1]. Therefore, theoretically, PTHFs with molecular weight of practical interest are amenable to tandem mass spectrometry combined with soft ionization methods. The MS/MS behaviors of polyethers such as polyethylene glycol (PEG) and polypropylene glycol (PPG) have been extensively studied [9-15], but only few papers on the MS/MS of PTHFs have been published [14-16].

In the MS/MS of PEG and PPG, four different product ion series have been identified: product ion series with hydroxyl (series A), vinyl (series B), and formyl end-groups (series C), as well as a distonic radical cation series formed by homolytic cleavage of the $\mathrm{C}-\mathrm{C}$ and $\mathrm{C}-\mathrm{O}$ bonds (series $\mathrm{D}$ ) [9-15]. Very recently, a new series formed by elimination of a $\mathrm{C}_{2} \mathrm{H}_{5} \mathrm{O}_{2}$ unit from the doubly lithiated PEG was also observed [13]. In contrast, MS/MS of singly lithiated PTHF showed the presence of series A and B with relatively high abundance, but series $C$ ions appeared with a low abundance [14, 15]. However, no formation of other series has been observed in the case of lithiated PTHF. 
To our best knowledge, no detailed report on the fragmentation properties of PTHF as a function of the size, collision energy, and charge state has been issued.

The objective of this work was to study the fragmentation behavior of singly and doubly lithiated PTHF generated by ESI under energy-dependent collisioninduced dissociation (CID). Another goal was to investigate the effect of the collision energy on the resulting MS/MS spectra of the singly and doubly lithiated PTHF, and to establish relationships between the collision energy and the relative intensities of some product and precursor ions.

\section{Experimental}

\section{Chemicals}

All chemicals used were received from Aldrich (Steinheim, Germany). PTHF [ $\left.\mathrm{HO}\left(\mathrm{CH}_{2} \mathrm{CH}_{2} \mathrm{CH}_{2} \mathrm{CH}_{2} \mathrm{O}\right)_{n} \mathrm{H}\right]$ with a number-average molecular weight of $650 \mathrm{~g} / \mathrm{mol}$ was dissolved in methanol at a concentration of $2 \mathrm{mM}$. To obtain lithiated adducts of PTHF in ESI, a solution of $\mathrm{LiCl}$ in methanol was added to the PTHF solutions to obtain concentration of $1 \mathrm{mM}$ for PTHF and $\mathrm{LiCl}$. Deuterated PTHF sample was obtained by dissolving $\mathrm{LiCl}$ and PTHF in $\mathrm{CH}_{3} \mathrm{OD}$ from Isotech Inc. (Miamisburg, OH, USA) in the same way as described above.

\section{Electrospray Quadrupole Time-of-Flight MS/MS (ESI-Q-TOF)}

MS/MS measurements were performed with a MicroTOF-Q type Qq-TOF MS instrument equipped with an ESI source from Bruker (Bruker Daltoniks, Bremen, Germany). The sample solutions were introduced directly into the ESI source with a syringe pump (Cole-Parmer Ins. Co., Vernon Hills, IL, USA) at a flow rate of 3 $\mu \mathrm{L} / \mathrm{min}$. The temperature of the drying gas $\left(\mathrm{N}_{2}\right)$ was kept at $160 \mathrm{C}$. The needle voltage was $4 \mathrm{kV}$. For MS/MS experiments, nitrogen gas was used as the collision gas and the collision energies were varied in the range of $10-200 \mathrm{eV}$ (in the laboratory frame). The pressure in the collision cell was determined to be $8 \times 10^{-3} \mathrm{mbar}$. The precursor ions for MS/MS were selected with an isolation width of $m / z 5$. The MS/MS spectra were accumulated and recorded by a digitizer at a sampling rate of 2 $\mathrm{GHz}$. The mass spectra were calibrated externally using the exact masses of clusters $\left[(\mathrm{NaTFA})_{\mathrm{n}}+\mathrm{Na}\right]^{+}$generated from the electrosprayed solution of sodium trifluoroacetate (NaTFA). The mass spectra recorded were evaluated with the DataAnalysis 3.4 software from Bruker.

\section{Evaluation of the Survival Yield Curves}

The survival yield (SY) [17-19] is defined by eq 1 .

$$
\mathrm{SY}=\frac{\mathrm{I}_{\mathrm{p}}}{\mathrm{I}_{\mathrm{p}}+\sum \mathrm{F}_{\mathrm{i}}}
$$

where $I_{p}$ is the intensity of the precursor ion, and $\Sigma F_{i}$ is the sum of all fragment ion intensities.

The shape of the SY versus collision energy $(\mathrm{eV})$ or collision voltage $(\mathrm{V})$ curves is a sigmoid type and can be described by e.g., a two-parameter sigmoid function according to eq 2

$$
\mathrm{SY}=\frac{1}{1+\mathrm{a} e^{\mathrm{bCV}}}
$$

where $\mathrm{a}$ and $\mathrm{b}$ are constants and $\mathrm{CV}$ is the collision voltage.

It has been shown that a characteristic collision energy or collision voltage can be obtained at a voltage when the intensity of the precursor ion is equal to that of all fragment ions, i.e., at 50\% fragmentation (SY $=$ $0.5)[20,21]$. The value of the collision voltage at $\mathrm{SY}=$ $0.5\left(\mathrm{CV}_{50}\right)$ can be expressed by eq 3 using the parameters of eq 2.

$$
\mathrm{CV}_{50}=\frac{\ln (1 / \mathrm{a})}{\mathrm{b}}
$$

For fitting the parameters of the two-parameter sigmoid function (eq 2) to the experimental data, a home-made software utilizing the Gauss-Newton-Marquard procedure was applied.

\section{Results and Discussion}

$$
\begin{aligned}
& \text { MS/MS of the Singly Lithiated } \\
& \text { Polytetrahydrofuran }\left(\left[\mathrm{PTHF}+\mathrm{Li}^{+}\right)\right.
\end{aligned}
$$

As the sodiated and potassiated polyethers have been reported to exhibit no or very weak product ion signals [9-14], we focused our MS/MS studies on the lithiated PTHF.

The ESI-MS spectrum of the solution of PTHF $\left[\mathrm{HO}\left(\mathrm{CH}_{2} \mathrm{CH}_{2} \mathrm{CH}_{2} \mathrm{CH}_{2} \mathrm{O}\right)_{n} \mathrm{H}\right]$ in the presence of added $\mathrm{LiCl}$ salts leads to the formation of singly, doubly, and triply lithiated adduct ions (shown in the Supplemental Information, which can be found in the electronic version of this article). The latter could only be observed in low intensity. Interestingly, the series of doubly and triply lithiated PTHF adducts occurred approximately in the same $\mathrm{m} / \mathrm{z}$ range as the singly charged one, most probably due to the relatively large polydispersity of the PTHF sample. Hence, the fraction of the PTHF sample with higher molecular weight was dominantly multiple-charged whose $\mathrm{m} / \mathrm{z}$ values thus fall into the $\mathrm{m} / \mathrm{z}$ range of the singly charged one, causing a virtual overlapping of different charged states. However, this kind of charge state distribution did not prevent the selection of the desired adduct ion for MS/MS since each peak in the $\mathrm{m} / \mathrm{z}$ range of interest was well resolved 
and spaced enough making the identification and selection of the precursor ion accurate (the mass of the end-group and the repeat unit are 18 and $72 \mathrm{Da}$, respectively). In this series of experiments, singly lithiated adducts of PTHF ([PTHF $\left.+\mathrm{Li}^{+}\right)$were subjected to collision-induced dissociation (CID) to obtain structural information and to gain insight into the fragmentation properties. Figure 1 shows the product ion spectrum of $\left(\left[\mathrm{PTHF}+\mathrm{Li}^{+}\right.\right.$with a number of repeat units 10 , and Scheme 1 summarizes the different series appeared in the product ion spectrum.

As seen in Figure 1 and Scheme 1, three different series $A, B$, and $C$ occurred in the MS/MS spectrum. The $\mathrm{A}, \mathrm{B}$, and $\mathrm{C}$ series are similar to those observed in the MS/MS spectra of the analogous polyethylene glycol (PEG) and polypropylene glycol (PPG), thus these series were named accordingly [9-15]. The formations of series $\mathrm{A}, \mathrm{B}$, and $\mathrm{C}$ are also in line with those reported for PTHF using a MALDI quadrupole ion trap (QIT)-time-of-flight (TOF) [14] and a MALDI hybrid sector oa-TOF instrumentation [15]. In the MS/MS spectra of the lithiated PTHF, series A corresponds to the product ions formed by fragmentation along the whole polyether backbone to yield a series of fragment ions with the same end-groups carried by the precursor, i.e., $\mathrm{H}$ and $\mathrm{OH}$ groups. Series $\mathrm{B}$ and $\mathrm{C}$ are product ion series with vinyl and formyl chain-ends, respectively, as depicted in Scheme 1. Lithiated PEGs and PPGs exhibit two additional series with respect to PTHF: one distonic radical cation series denoted as series $\mathrm{D}$, which is formed by homolytic cleavage of the $\mathrm{C}-\mathrm{C}$ and $\mathrm{C}-\mathrm{O}$

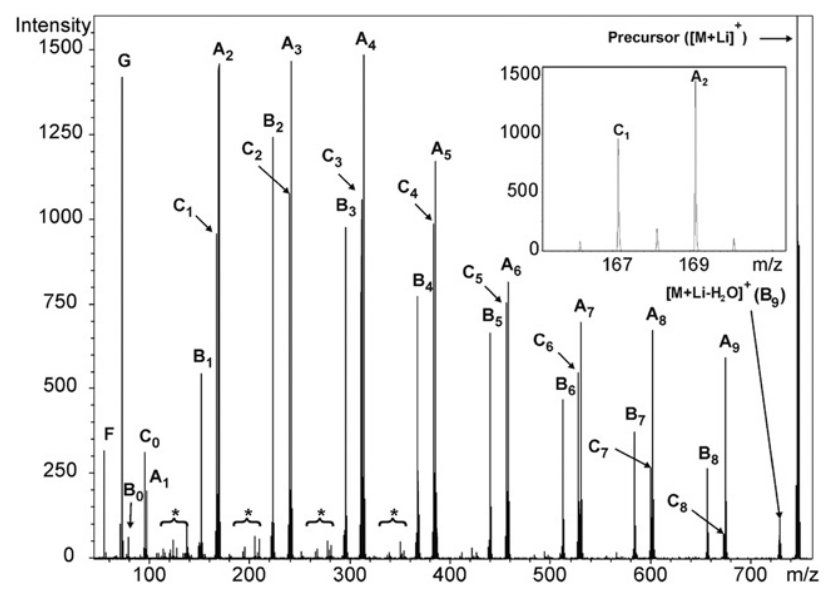

Figure 1. ESI-MS/MS of singly lithiated polytetrahydrofuran $\left(\left[\mathrm{PTHF}_{10}+\mathrm{Li}\right]^{+}\right.$) (with a number of repeat unit of $n=10$ ) recorded at $95 \mathrm{eV}$ laboratory frame collision energy. The numbers in the subscript stand for the number of repeat units as indicated in Scheme 1. The regions denoted by asterisk are due to the presence of low intensity product ion series of $[\mathrm{Li}+$ $\left.\mathrm{HO}\left(\mathrm{CH}_{2} \mathrm{CH}_{2} \mathrm{CH}_{2} \mathrm{CH}_{2} \mathrm{O}\right)_{n} \mathrm{CH}\left(\mathrm{CH}_{2}\right)_{\mathrm{m}}\right]^{+}(\mathrm{m}=0,1$, and 2$)$. The inset shows the partial ESI-MS/MS spectrum for product ions $\mathrm{C}_{1}$ and $\mathrm{A}_{2}$. The labeled $m / z$ values are: series $\mathrm{A}=25+72 \mathrm{x}$, series $\mathrm{B}=$ $79+72 x$, series $C=95+72 x(x=$ number of repeat units $)$ and 55 , 73,745 , and 727 for the $\mathrm{F}, \mathrm{G},[\mathrm{M}+\mathrm{Li}]^{+}$and $\left[\mathrm{M}+\mathrm{Li}-\mathrm{H}_{2} \mathrm{O}\right]^{+}$ions, respectively. bonds, and the other recently recognized series is produced by elimination of $\mathrm{C}_{2} \mathrm{H}_{5} \mathrm{O}_{2}$ units [13]. According to our MS/MS investigations, lithiated PTHF revealed also the formation of a very low intensity product ion series corresponding to the composition of $[\mathrm{Li}+$ $\left.\mathrm{HO}\left(\mathrm{CH}_{2} \mathrm{CH}_{2} \mathrm{CH}_{2} \mathrm{CH}_{2} \mathrm{O}\right)_{n} \mathrm{CH}\left(\mathrm{CH}_{2}\right)_{\mathrm{m}}\right]^{+}(\mathrm{m}=0,1$, and 2). These latter PTHF product ion series are rather similar to the series D ions of PEG and PPG in a manner that they were formed by the cleavage of $\mathrm{C}-\mathrm{C}$ bonds. However, the low intensity PTHF product ion series are of even electron-numbered $\left(\mathrm{EE}^{+}\right)$unlike the series $\mathrm{D}$ ions of PEG and PPG, which are radical ones (oddelectron numbered, $\mathrm{OE}^{+}$). Another dissimilarity between the fragmentation pattern of lithiated PTHF and its PEG and PPG analogs is that the lithiated PTHF yields more abundant product ions formed by the loss of an $\mathrm{H}_{2} \mathrm{O}$ molecule from the precursors. Furthermore, we also observed the formation of nonlithiated product ions at $\mathrm{m} / \mathrm{z} 73$ (denoted as ion G) and 55 (named as ion F) in the case of lithiated PTHF (as depicted in Scheme 1) which, to the best of our knowledge, have not been reported yet. No higher homologues of ions $G$ and $F$ were found. The formation of ion $G$ is most likely accompanied by the generation of a neutral Li-salt. The compositions of these two ions were supported by means of accurate mass measurements and by using PTHF dissolved in deuterated methanol. On the other hand, in the MS/MS of the doubly deuterated PTHF the $\mathrm{m} / \mathrm{z}$ of ion $\mathrm{G}$ shifted from 73 to 74 , whereas that of ion $\mathrm{F}$ did not change, in good agreement with the species proposed in Scheme 1. It should be emphasized, however, that the structures for the G- and F-ion presented in Scheme 1 are only tentative but their compositions and the number of the changeable protons are unambiguous.

It can also be concluded from this observation that ion $\mathrm{G}$ originated from charge retention on the dissociating polyether chain-end and not from an internal cleavage of the polyether backbone. The doubly deuterated PTHF with six repeat units $\left(\mathrm{PTHF}_{6}\right)$ was also subjected to MS/MS to gain deeper insight into the PTHF fragmentation mechanism. The intensity ratio of the singly and doubly deuterated product ions was recorded as a function of the collision energy. The fraction of the singly deuterated product ion with a number of repeat units $\mathrm{x}$ with respect to that of the doubly deuterated species $\left(\phi_{\mathrm{x}}\right)$ can be expressed by eq 4 .

$$
\phi_{\mathrm{X}}=\frac{\mathrm{I}_{\mathrm{A}_{\mathrm{x}, \mathrm{d}}}}{\mathrm{I}_{\mathrm{A}_{\mathrm{x}, \mathrm{d}}}+\mathrm{I}_{\mathrm{A}_{\mathrm{x}, \mathrm{dd}}}}
$$

where $\mathrm{I}_{\mathrm{A}_{\mathrm{x}, \mathrm{d}}}$ and $\mathrm{I}_{\mathrm{A}_{\mathrm{x}, \mathrm{dd}}}$ are the intensities of the singly and doubly deuterated product ions with a number of repeat units $\mathrm{x}$.

Figure 2 shows the dependence of $\phi_{x}$ on the collision energy for the product ions $\mathrm{A}_{5}^{+}, \mathrm{A}_{4}^{+}$, and $\mathrm{A}_{3}^{+}$.

As can be seen in Figure 2, the $\mathrm{A}_{5}^{+}$fragment ion is formed predominantly by elimination of a $\mathrm{C}_{4} \mathrm{H}_{8} \mathrm{O}$ unit from the precursor. At low collision energy $(40 \mathrm{eV})$ only ca. $8 \%$ of $\mathrm{A}_{5}^{+}$was formed by elimination of a $\mathrm{C}_{4} \mathrm{H}_{7} \mathrm{DO}$ 


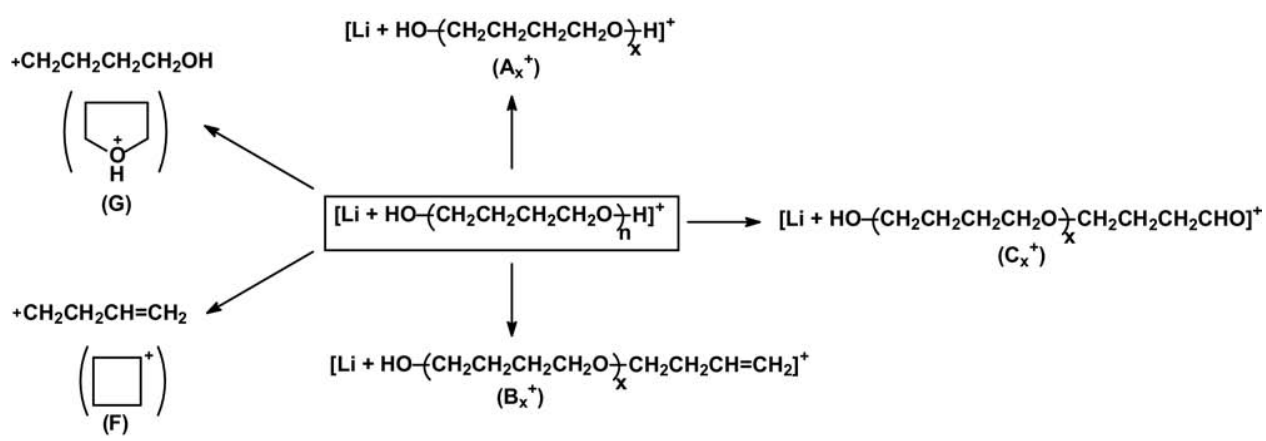

Scheme 1. The proposed structures of the product ions formed from the singly lithiated polytetrahydrofuran.

unit. However, the fraction of the $\mathrm{A}_{5}^{+}$fragment ion due to the elimination of a $\mathrm{C}_{4} \mathrm{H}_{7} \mathrm{DO}$ unit increases with the collision energy. The eliminated $\mathrm{C}_{4} \mathrm{H}_{8} \mathrm{O}$ and $\mathrm{C}_{4} \mathrm{H}_{7} \mathrm{DO}$ units were found in the MS/MS spectra in the form of $\left[\mathrm{Li}+\mathrm{C}_{4} \mathrm{H}_{8} \mathrm{O}\right]^{+}$and $\left[\mathrm{Li}+\mathrm{C}_{4} \mathrm{H}_{7} \mathrm{DO}\right]^{+}$ions, i.e., $\mathrm{B}_{\mathrm{o}}^{+}$ products ions. Consistent with the finding for the $\mathrm{A}_{5}^{+}$ ion, it was observed that at low collision energies, overwhelmingly [ $\left.\mathrm{Li}+\mathrm{C}_{4} \mathrm{H}_{8} \mathrm{O}\right]^{+}$was formed, however, at higher collision energies the $\left[\mathrm{Li}+\mathrm{C}_{4} \mathrm{H}_{7} \mathrm{DO}\right]^{+}$ion also appeared. This suggests that the $\mathrm{A}$ and $\mathrm{B}$ fragment ions are formed simultaneously, and the chain-end plays a significant role in the formation of the $\mathrm{A}_{5}^{+}$ion. It is also evident from Figure 2 that $\mathrm{A}_{4}^{+}$and $\mathrm{A}_{3}^{+}$are observed as partly dideuterated ions with a decreasing fraction $\mathrm{A}_{4}^{+}>$ $\mathrm{A}_{3}^{+}$. From the results presented in Figure 2, it can be concluded that the transfer of a hydrogen from an internal tetramethylene oxide unit becomes more pronounced with the increasing collision energy and the

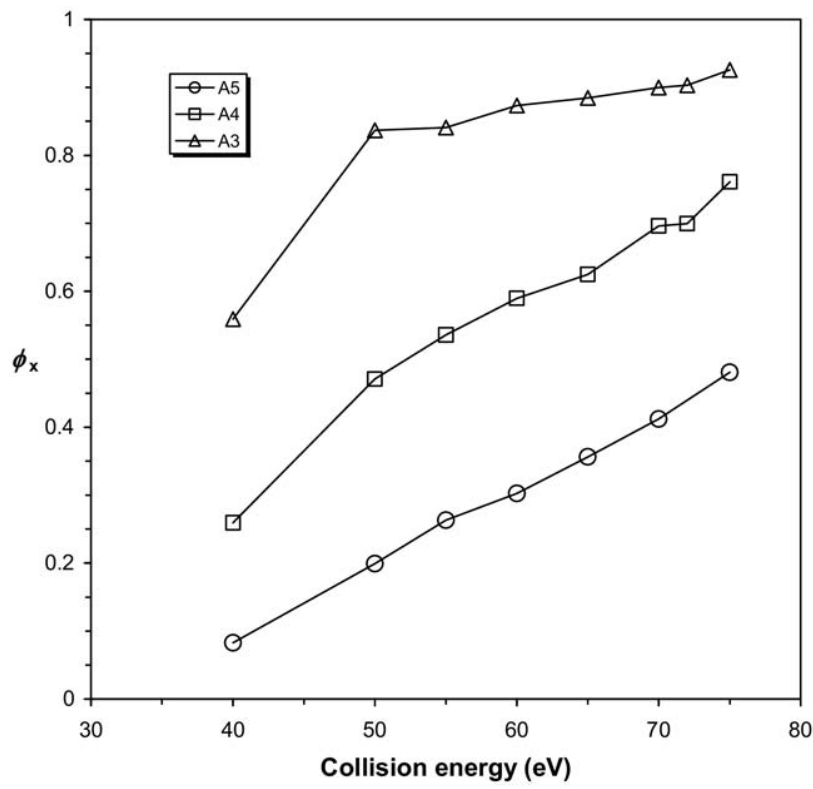

Figure 2. The intensity ratio $\left(\phi_{\mathrm{x}}\right)$ of the singly and doubly deuterated product ions calculated by eq 4 for product ions $\mathrm{A}_{5}, \mathrm{~A}_{4}$, and $\mathrm{A}_{3}$ formed from dideuterated $\left[\mathrm{PTHF}_{6}+\mathrm{Li}\right]^{+}$precursor ion $(n=6)$ as a function of collision energy. distance between the hydroxyl hydrogen (end-group $\mathrm{OH})$ and the dissociating ether bonds.

To evaluate the relative contribution of the different fragmentation pathways leading to the formation of the product ion series $A, B$ and $C$, as well as product ion $G$ as a function of the collision energy, breakdown diagrams and modified breakdown diagrams [22] were constructed (Figure 3). The relative intensity of ion $\mathrm{F}$ compared with that of the other product ions was very small, therefore, it was not included in the breakdown diagrams.

As seen in Figure $3 a$ and $b$, the series $A$ ions are dominant over all of the other series throughout the collision energy range of $25-60 \mathrm{eV}$. However, at higher collision energy, the dominance of series $\mathrm{A}$ tends to decrease and above ca. $60 \mathrm{eV}$ the series $\mathrm{C}$ ions became more pronounced. The fraction of $\mathrm{G}$ ion increases with the collision energy. The relative intensity of series $C$ increases more steeply than that of series B, and at higher collision energies the abundance of series $C$ clearly exceeds that of series B. As seen in Figure 3a, the abundance of series $C$ and series $B$ are significantly different at all collision energies except at ca. $52 \mathrm{eV}$, where the two curves intercept each other. The breakdown diagram for $\mathrm{PTHF}_{8}$ shown in Figure $3 \mathrm{c}$ and $\mathrm{d}$ are rather similar to that presented for $\mathrm{PTHF}_{4}$. The most significant differences in the breakdown diagrams shown in Figure 3a and $\mathrm{c}$ is the shift to higher collision energy with the increasing mass (size) of the precursor ion and that the breakdown curve for G-ion gets closer to those of series A and B. Furthermore, as judged from the breakdown diagrams in Figure 3, series A and B change closely together, suggesting that the series A ions are formed along with the series B ions but with different relative intensity, whereas the series $C$ ions are most likely originated from another parallel process having higher activation energy. In the MS/MS spectra of PEG and PPG, the intensity of series B and series C were found to be almost identical, revealing a charge remote fragmentation pathway for the formation of the product ions with vinyl (series B) and formyl (series C) termini [9]. However, as evidenced from Figure 3, this is not the case for lithiated PTHF. According to the 

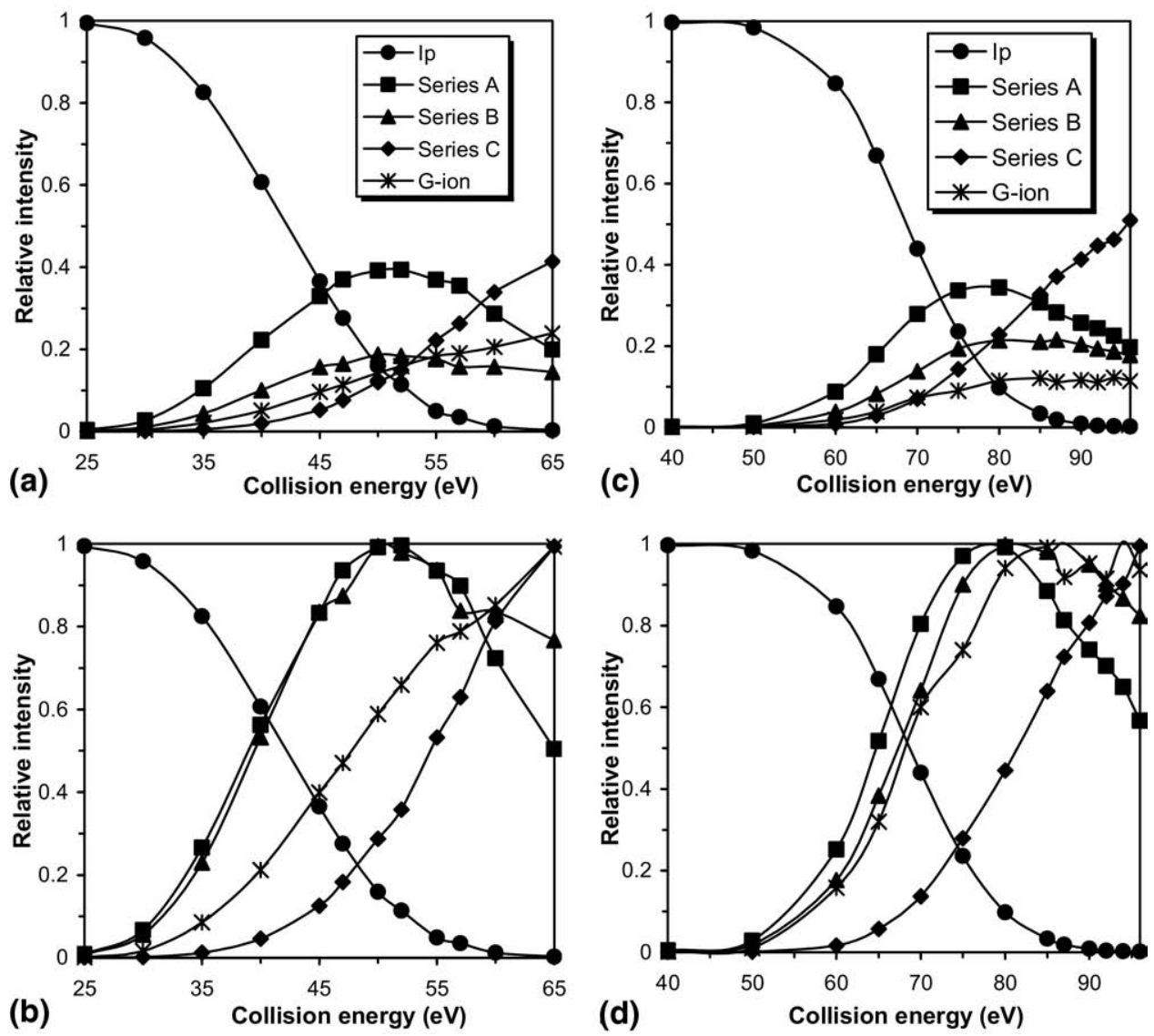

Figure 3. Breakdown diagram (a) and modified breakdown curves (b) for the product ions formed from the $\left[\mathrm{PTHF}_{4}+\mathrm{Li}\right]^{+}(n=4)$ precursor ion. Breakdown diagram (c) and modified breakdown curves $(\mathbf{d})$ for the product ions formed from the $\left[\mathrm{PTHF}_{8}+\mathrm{Li}\right]^{+}(n=8)$ precursor ion. The intensity for a given series was obtained by summing intensities of all-fragment ions belonging to that series. The relative intensity was calculated as the ratio of the intensity of a given product ion to that of all product ion intensities plus precursor ion intensity. The modified breakdown curves were constructed by normalization of relative intensity of each product ion series to 1 .

experimental results, series A and series B are likely formed together by charge-induced fragmentation (charge facilitates the fragmentation). Depending on the position of the $\mathrm{Li}^{+}$-ion at the time of fragmentation, either series A or series B will be observed. The lower intensities of the B series compared with the A series in the MS/MS spectra are most probably due to the lower affinity of the vinyl-terminated fragment to the cation than to the alcoholic end-group of series A. Series C seems to be formed via a different charge-induced fragmentation channel. The potential lack of chargeremote fragmentation for the formation of series $\mathrm{B}$ and $\mathrm{C}$ in the case of lithiated PTHF is most probably because an eight-member intermediate should be formed for charge-remote fragmentation to occur, which is less stable than a six-member intermediate formed from PEG and PPG as it was also concluded from a MALDIquadrupole ion trap-time-of-flight study with lithiated PTHF [14]. (Note that PTHF carries four backbone carbon atoms/repeat units, whereas PEG or PPG has two backbone carbons atoms/repeat units.)

\section{MS/MS of the Doubly Lithiated Polytetrahydrofuran ([PTHF $\left.+2 \mathrm{Li}]^{2+}\right)$}

The singly lithiated PTHF could be fragmented up to oligomers containing 15 repeat units. For higher oligomers MS/MS failed due to the complete loss of ion signal under our instrumental conditions. Therefore, the fragmentation studies were extended to the doubly lithiated PTHF, expecting that higher oligomers would be amenable to MS/MS investigation and, hence, for structural elucidation. Indeed, these experiments showed that the doubly lithiated PTHF oligomers with a number of repeat units ranging from 8 to 27 (corresponding to a mass range of $600-2000 \mathrm{Da}$ ) can be readily fragmented. Figure 4 shows the MS/MS spectrum of $\left([\mathrm{PTHF}+2 \mathrm{Li}]^{2+}\right.$ with a number of repeat units $n=10$.

As seen in Figure 4, singly and doubly lithiated product ions were formed from the doubly charged precursor ion. The singly charged series A, B, and C, as well as the $G$ and $F$ ions are identical to those observed in the MS/MS of the singly lithiated PTHF. On the other 


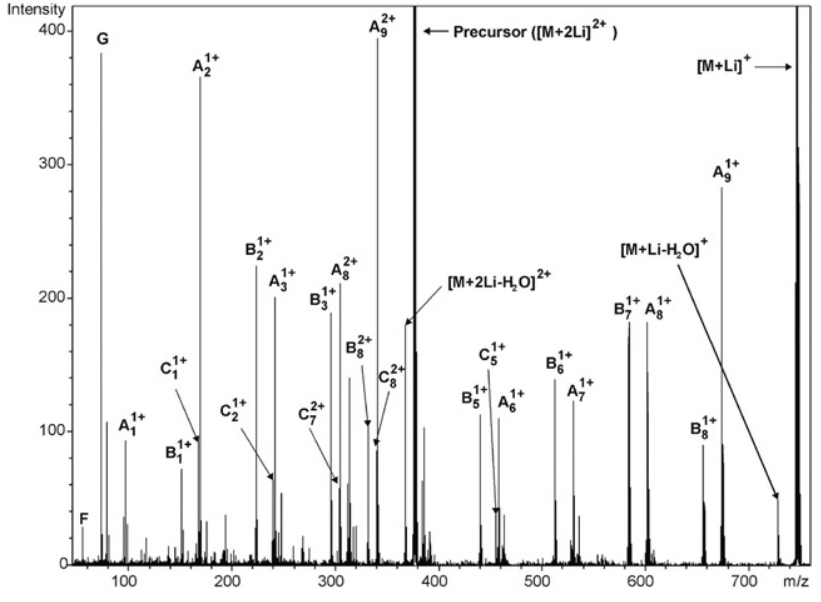

Figure 4. ESI-MS/MS of doubly lithiated polytetrahydrofuran $\left(\left[\mathrm{PTHF}_{10}+2 \mathrm{Li}\right]^{2+}\right.$ ) (with a number of repeat unit of $n=10$ ) recorded at $42 \mathrm{~V}$ collision voltage. The numbers in the subscript stand for the number of repeat units. The labeled $m / z$ values are: series $\mathrm{A}^{1+}=25+72 \mathrm{x}$, series $\mathrm{B}^{1+}=79+72 \mathrm{x}$, series $\mathrm{C}^{1+}=95+$ $72 \mathrm{x}$, series $\mathrm{A}^{2+}=16+36 \mathrm{x}$, series $\mathrm{B}^{2+}=43+36 \mathrm{x}$, series $\mathrm{C}^{2+}=$ $51+36 x(x=$ number of repeat units), and 55, 73, 745, 727, 376, 367 for the $\mathrm{F}, \mathrm{G},[\mathrm{M}+\mathrm{Li}]^{+},\left[\mathrm{M}+\mathrm{Li}-\mathrm{H}_{2} \mathrm{O}\right]^{+},[\mathrm{M}+2 \mathrm{Li}]^{2+}$, and $[\mathrm{M}+$ $\left.2 \mathrm{Li}-\mathrm{H}_{2} \mathrm{O}\right]^{2+}$ ions, respectively.

hand, the doubly lithiated series of fragment ions such as $\mathrm{A}_{\mathrm{x}}^{2+}, \mathrm{B}_{\mathrm{x}}^{2+}$, and $\mathrm{C}_{\mathrm{x}}^{2+}$ are also occurred. The end-groups of the doubly charged product ion series, i.e., those bearing two $\mathrm{Li}^{+}$-ion on their chains are identical with that of the corresponding singly charged ones, so it was labeled accordingly. It was observed in the MS/MS of the doubly lithiated PTHF that among the doubly lithiated product ions series $\mathrm{A}_{x}^{2+}$ and $\mathrm{B}_{\mathrm{x}}^{2+}$ were present with the highest intensity. $\mathrm{A}_{x}^{2+}$ and $\mathrm{B}_{\mathrm{x}}^{2+}$ showed monotonously increasing intensity with the number of repeat units $x$, while the members of series $C_{x}^{2+}$ were assigned with relatively low intensities. For example, in the MS/MS spectrum of $\left[\mathrm{PTHF}_{23}+2 \mathrm{Li}\right]^{2+}$ (shown in the Supplemental Information) the intensities of the product ions $\mathrm{A}_{x}^{2+}$ decreased monotonously in the order of $\mathrm{A}_{22}^{2+}, \mathrm{A}_{21}^{2+}, \mathrm{A}_{20}^{2+}$, and so on, up to $\mathrm{A}_{10}^{2+}$ with the abundance ratio of ca. $60 / 1\left(\mathrm{~A}_{22}^{2+}\right.$ to $\mathrm{A}_{10}^{2+}$, at $80 \mathrm{~V}$ collision voltage). On the other hand, in the MS/MS of $\left[\mathrm{PTHF}_{10}+2 \mathrm{Li}\right]^{2+}$ presented in Figure $4, \mathrm{~A}_{7}^{2+}$ appears only with a very low intensity. Furthermore, MS/MS of $\left[\mathrm{PTHF}_{8}+2 \mathrm{Li}\right]^{2+}$ also revealed that the $\mathrm{A}_{7}^{2+}$ ion was formed only with extremely low abundance. Therefore, it is reasonable to conclude that the fragmented chains must contain at least eight repeat units to carry two $\mathrm{Li}^{+}$-ions.

The $[\mathrm{PTHF}+\mathrm{Li}]^{+}$ion can also be detected due to the loss of one $\mathrm{Li}^{+}$-ion from the precursor ion. The presence of the singly charged product ion series in the lower and higher mass region of the MS/MS spectrum indicates that fragmentation of the doubly lithiated precursor ion into two singly charged lithiated product ion series takes place by chain-cleavage. This is supported partly by the fact that at low collision energies besides $\mathrm{A}_{16}^{1+}, \mathrm{A}_{15}^{1+}, \mathrm{A}_{14}^{1+}$, the product ions $\mathrm{A}_{3}^{1+}$ and $\mathrm{A}_{2}^{1+}$ can also be detected with low intensity in the MS/MS spectrum of $\left[\mathrm{PTHF}_{17}+\mathrm{Li}\right]^{2+}$. Hence, $\mathrm{A}_{3}^{+}$and $\mathrm{A}_{2}^{+}$can not originate from a multiple dissociation; they result most likely from simple cleavages of the precursor polymer chain. In addition, another fragmentation channel leading to the formation of a singly charged one is also possible: by consecutive dissociation of the doubly lithiated fragment ions into the corresponding singly charged one upon elimination of one $\mathrm{Li}^{+}$-ion.

To get deeper insight into the evolution of the different product ion series formed from the doubly lithiated PTHF as a function of collision voltage/energy, breakdown curves were derived. The breakdown curves and the modified breakdown diagrams for $\left[\mathrm{PTHF}_{10}+2 \mathrm{Li}\right]^{2+}$ and $\left[\mathrm{PTHF}_{15}+2 \mathrm{Li}\right]^{2+}$ are depicted in Figure 5.

As seen in Figure $5 b$ and $d$, the normalized breakdown curves for $\left[\mathrm{PTHF}_{10}+2 \mathrm{Li}\right]^{2+}$ and $\left[\mathrm{PTHF}_{15}+\right.$ $2 \mathrm{Li}]^{2+}$ are very similar, but those for the latter are shifted to higher collision energy. Again, it can be concluded from these modified breakdown diagrams that $\mathrm{A}_{\mathrm{x}}^{1+}$ and $\mathrm{B}_{\mathrm{x}}^{1+}$ are likely formed together, while the $\mathrm{C}_{\mathrm{x}}^{1+}$ ion are produced in a process having higher activation energy. Similar conclusions can be drawn for the product ion series $\mathrm{A}_{\mathrm{x}}^{2+}, \mathrm{B}_{\mathrm{x}}^{2+}$, and $\mathrm{C}_{\mathrm{x}}^{2+}$ but they appear at lower collision energy than the corresponding singly charged homologues and disappear at higher collision energies. The fact that the relative intensities of $\mathrm{A}_{\mathrm{x}}^{2+}, \mathrm{B}_{\mathrm{x}}^{2+}$, and $\mathrm{C}_{\mathrm{x}}^{2+}$ decrease at higher collision energy may be due to the dissociation of doubly charged fragment ions by chain-cleavage into the corresponding singly charged product ions, and/or due to the loss of one $\mathrm{Li}^{+}$ion from the doubly lithiated fragment ion. Interestingly, the breakdown curve for the G-ion runs very close to those for the $A_{x}^{1+}$ and $B_{x}^{1+}$ series, suggesting approximately the same activation energies for the processes generating the $\mathrm{A}_{\mathrm{x}}^{1+}, \mathrm{B}_{\mathrm{x}}^{1+}$, and $\mathrm{G}$ ions. It is also seen in Figure $5 \mathrm{a}$ and $\mathrm{c}$ that the relative intensities change with the mass of the precursor. One of the most notable differences is that the abundances of the product ion formed by loss of one $\mathrm{Li}^{+}$ion from the precursor decrease with the increasing precursor ion mass.

\section{Effect of the Size on the Survival Yield of the Singly and Doubly Lithiated PTHF}

In our further work, the dependences of the survival yield (SY) [17-19] on the collision energy/voltage were studied. The values of $\mathrm{CV}_{50}$, i.e., the collision voltage/ energy necessary to achieve $50 \%$ fragmentation (SY $=$ 0.5) $[20,21]$ were obtained as detailed in the Experimental section. In addition, the values of $\mathrm{CV}_{50}$ were also determined by a linear two-point interpolation. Interestingly, the two methods gave practically the same $\mathrm{CV}_{50}$ values within $0.3 \mathrm{~V}$. The $\mathrm{CV}_{50}$ values plotted as a function of $m / z$ for the singly and doubly lithiated PTHF are shown in Figure 6.

As seen in Figure 6, linear correlations between the $\mathrm{CV}_{50}$ and $\mathrm{m} / \mathrm{z}$ values were found for both the singly and the doubly lithiated PTHF, i.e., $\mathrm{CV}_{50}$ increases linearly 

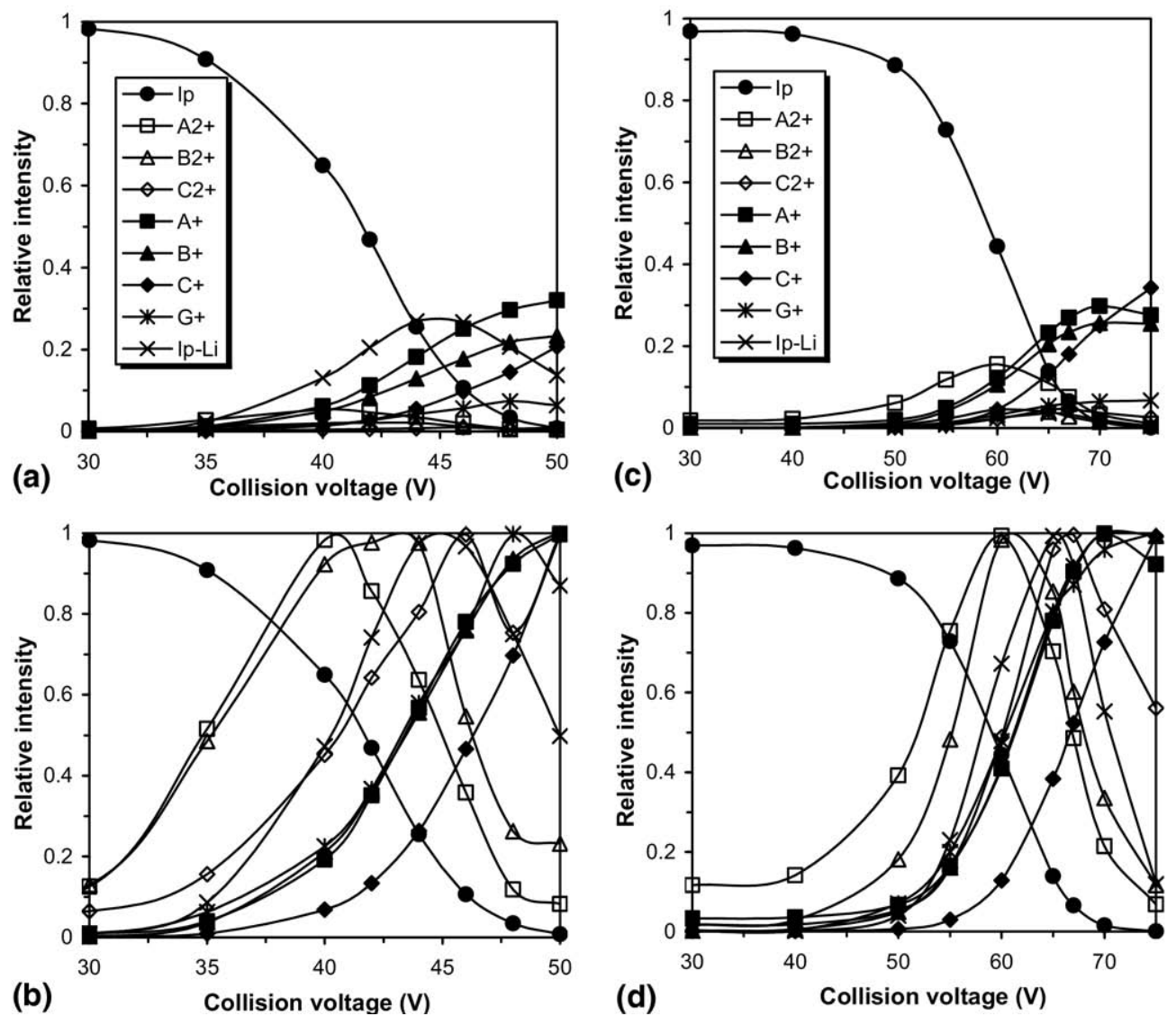

Figure 5. Breakdown diagram (a) and modified breakdown curves (b) for the product ions formed from the $\left[\mathrm{PTHF}_{10}+2 \mathrm{Li}\right]^{2+}(n=10)$ precursor ion. Breakdown diagram (c) and modified breakdown curves (d) for the product ions formed from the $\left[\mathrm{PTHF}_{15}+2 \mathrm{Li}\right]^{2+}(n=15)$ precursor ion. The breakdown and the modified breakdown curves were obtained as outlined in Figure 3 caption.

with the $m / z$. Although a small intercept can be found on the $\mathrm{CV}_{50}$ versus $\mathrm{m} / \mathrm{z}$ plot, the practical interest and utilization of such a relationship is evident: it allows an easy adjustment of the collision voltage, and hence the collision energy to obtain reasonable fragmentation necessary for structural identification. Similarly, linear correlation between the $\mathrm{CV}_{50}$ and the molecular weight was also found for lithiated PEG independently of the MS instrumentation (triple quadrupole, ion-trap, quadrupole time-of-flight) and of the charge state (data up to triply charged were reported) [21]. Therefore, it is promising that such kind of correlation seems to be general for polymers, at least for polyethers. However, an exact theoretical explanation for this particular correlation is still lacking. A tentative explanation for the linearity of $\mathrm{CV}_{50}$ versus size or degrees of freedom (DOF) observed also in our PEG studies can be found in ref 20 (DOF is closely related to the molecular weight). The same explanation holds for $\mathrm{CV}_{50}-\mathrm{m} / \mathrm{z}$ linearity of PTHF.

It can also be observed in Figure 6 that the $\mathrm{CV}_{50}$ values of the singly lithiated PTHF are a little bit above those of the doubly lithiated ones, indicating that the doubly charged PTHF requires lower collision voltage to obtain $S Y=0.5$ than the singly charged species with the same $m / z$. Exactly the same behavior was experienced during our PEG studies [21] and our current investigations on PPG. The possible reasons for this particular property are also compiled in reference [21], therefore, they are not discussed here.

Another possibility to study the energetics of fragmentation could be the construction of a center-of-mass energy at $50 \%$ fragmentation versus $\mathrm{m} / \mathrm{z}$ (or DOF) as suggested by one of our reviewers. However, such kind of a plot would be very helpful only in the case of a single collision. Moreover, under our instrumental conditions multiple collisions occur, and this kind of plot does not account for the increase in the number of collisions, as the mass increases due to the increase in the collision cross-section, neither the conformation effect nor the energy-transfer efficiency that may change also with the collision energy. Therefore, from both theoretical and practical points of view, we believe that in the case of multiple collisions, the use of the laboratory frame energy (at 50\% fragmentation) is more appropriate for presenting the energetics of mass-dependent fragmentations. For the sake of comparison, the center-of-mass energy at 50\% fragmentation $\left(\mathrm{E}_{\text {com50 }}\right)$ versus $m / z$ plot for PTHF is shown in the Supplemental Information. 


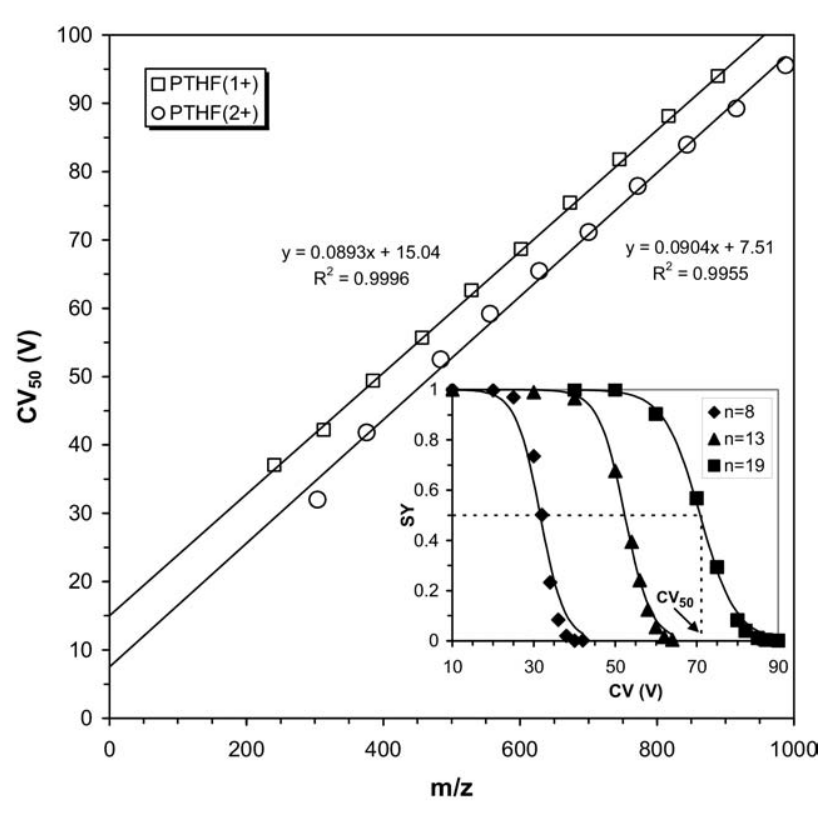

Figure 6. The variation of $\mathrm{CV}_{50}$ value with $\mathrm{m} / \mathrm{z}$ for the singly $[\operatorname{PTHF}(1+)]$ and doubly charged $[\operatorname{PTHF}(2+)]$ polytetrahydrofuran. The inset shows the survival yield (SY) versus collision voltage $(\mathrm{CV})$ curves for doubly charged polytetrahydrofuran with a number of repeat units of $n=8,13$, and 19. The solid line in the inset represents the fitted curves by eq 2 . The fitted parameters are: $\mathrm{a}=2.42 \times 10^{-5}$ and $\mathrm{b}=0.337$ for $n=8, \mathrm{a}=7.77 \times 10^{-8}$ and $\mathrm{b}=0.313$ for $n=13$, and $\mathrm{a}=1.08 \times 10^{-7}$ and $\mathrm{b}=0.226$ for $n=19$.

\section{Conclusions}

The collision-induced dissociation of the singly and doubly lithiated PTHF showed the formation of fragment ions similar to those formed from its analogs such as polyethylene glycol (PEG) and polypropylene glycol (PPG) but some significant dissimilarities have been observed. (1) No formation of distonic series was observed in the case of lithiated PTHF. (2) Lithiated PTHF yields more abundant product ions that are formed by the loss of an $\mathrm{H}_{2} \mathrm{O}$ molecule from the precursors than its PEG and PPG analogs. (3) The formation of nonlithiated product ions (G- and F-ions) were observed in the MS/MS spectra of PTHF. Similar cations were absent in the MS/MS spectra of the analogous polyethers. Evaluation of the breakdown curves for lithiated PTHF revealed that the series A and B ions are formed most likely together, whereas the series $C$ ions are produced in a process with higher activation energy. Furthermore, our survival yield analysis showed that the size $\mathrm{m} / \mathrm{z}$, hence the DOF, has a primary role in the determination of the SY values. Undoubtedly, one of the most practical interests is because SY (at 0.5 ) linearly correlates with the collision energy/voltage. Therefore, such kind of simple relationship between the size of the structurally similar polymers and the instrumental parameters allows the easy selection of the appropriate collision energy/voltage to obtain a fragmentation extent necessary for structural evaluation. The linear correlation between the size and the $\mathrm{CV}_{50}$ observed for
PEG [22] and also for PTHF (present study) and PPG (preliminary results) shows that the DOF effects are general for polymers, especially for polyethers. If such a linear correlation is valid for other types of polymers, e.g., polyesters or polyamides, independently of the MS instrumentation, it may greatly reduce the MS/MS analysis time of structurally similar polymers. This is particularly important in MS analysis combined with a separation technique such as high-performance liquid chromatography (HPLC) or size-exclusion chromatography (SEC). In this case, the appropriate collision energy/voltage to obtain reasonable fragmentation for the structurally similar polymers can easily be adjusted depending on the eluting mass.

\section{Acknowledgments}

This work was financially supported by grants K-72,524 and MU-00,204/2001 given by OTKA (National Scientific Research Fund, Hungary) and grant GVOP-3.2.1.-2004-04-0152/3.0. A.M. thanks the 6th Framework Program of the European Community for funding the POLY-MS project (MEST-CT-2005-021029).

\section{Appendix A Supplementary Material}

Supplementary material associated with this article may be found in the online version at doi:10.1016/ j.jasms.2010.06.013.

\section{References}

1. Dreyfuss, P. Polytetrahydrofurans. In Handbook of Elastomers; Bhowmick, A. K.; Stephens, L. H., Eds. Marcel Dekker: New York, 2000; Chap. 27, pp 723-734.

2. Chen, J. H.; Wei, J.; Chang, C. Y.; Laiw, R. F.; Lee, Y. D. Studies on Segmented Polyetherurethane for Biomedical Application: Effects of Composition and Hard-Segment Content on Biocompatibility. J. Biomed. Mater. Res. 1984, 18, 939-951.

3. Martin, D. J.; Poole-Warren, L. A.; Gunatillake, P. A.; McCarthy, S. J.; Meijs, G. F.; Schindhelm, K. Polydimethylsiloxane/Polyether-Mixed Macrodiol-Based Polyurethane Elastomers: Biostability. Biomaterials 2000, 21, 1021-1029.

4. Solis-Correa, R. E.; Vargas-Coronado, R.; Aguilar-Vega, M.; CauichRodriguez, J. V.; San Roman, J.; Marcos, A. Synthesis of HMDI-Based Segmented Polyurethanes and Their Use in the Manufacture of Elastomeric Composites for Cardiovascular Applications. J. Biomater. Sci. Polym. Ed. 2007, 18, 561-578.

5. Fromstein, J. D.; Woodhause, K. A. Polyurethane Biomaterials. In Encyclopedia of Biomaterials and Biomedical Engineering; Wnek, G. E.; Bowlin, G. L., Eds. Informa Healthcare Inc.: New York, 2008; pp 2304-2313.

6. Karas, M.; Hillenkamp, F. Laser Desorption Ionization of Proteins with Molecular Masses Exceeding 10,000 Daltons. Anal. Chem. 1988, 60, 2299-2301.

7. Tanaka, K.; Waki, H.; Ido, Y.; Akita, S.; Yoshida, T. Protein and Polymer Analyses up to $m / z 100,000$ by Laser Ionization Time-of-Flight Mass Spectrometry. Rapid Commun. Mass Spectrom. 1988, 2, 151-153.

8. Wong, S. F.; Meng, C. K.; Fenn, J. B. Multiple Charging in Electrospray Ionization of Poly(Ethylene Glycols). J. Phys. Chem. 1988, 92, 546-550.

9. Lattimer, R. P. Tandem Mass Spectrometry of Lithium-Attachment Ions from Polyglycols. J. Am. Soc. Mass Spectrom. 1992, 3, 225-234.

10. Lattimer, R. P. Tandem Mass Spectrometry of Poly(Ethylene Glycol) Lithium-Attachment Ions J. Am. Soc. Mass Spectrom. 1994, 5, 1072-1080.

11. Selby, T. L.; Wesdemiotis, C.; Lattimer, R. P. Dissociation Characteristics of $[\mathrm{M}+\mathrm{X}](+)$ Ions $(\mathrm{x}=\mathrm{H}, \mathrm{Li}, \mathrm{K})$ from Linear and Cyclic Polyglyols. J. Am. Soc. Mass Spectrom. 1994, 5, 1081-1092.

12. Chen, R.; Li, L. Lithium and Transition Metal Ions Enable Low Energy Collision-Induced Dissociation of Polyglycols in Electrospray Ionization Mass Spectrometry. J. Am. Soc. Mass Spectrom. 2001, 12, 832-839.

13. Girod, M.; Carissan, Y.; Humbel, S.; Charles, L. Tandem Mass Spectrometry of Doubly Charged Poly(Ethylene Oxide) Oligomers Produced by Electrospray Ionization. Int. J. Mass Spectrom. 2008, 272, 1-11. 
14. Okuno, S.; Kiuchi, M.; Arakawa, R. Structural Characterization of Polyethers Using Matrix-Assisted Laser Desorption/Ionization Quadrupole Ion Trap Time-of-Flight Mass Spectrometry. Eur. J. Mass Spectrom. 2006, 12, 181-187.

15. Jackson, A. T.; Green, M. R.; Bateman, R. H. Generation of End-Group Information from Polyethers by Matrix-Assisted Laser Desorption/ Ionization Collision-Induced Dissociation Mass Spectrometry. Rapid Commun. Mass Spectrom. 2006, 20, 3542-3550.

16. Lattimer, R. P. Mass Spectral Analysis of Low-Temperature Pyrolysis Products from Poly(Tetrahydrofuran). J. Anal. Applied Pyrol. 2001, 57, 57-76.

17. Derwa, F.; Pauw, E. D.; Natalis, P. New Basis for a Method for the Estimation of Secondary Ion Internal Energy-Distribution in Soft Ionization Techniques. Org. Mass Spectrom. 1991, 26, 117-118.

18. Guo, X. H.; Duursma, M. C.; Kistemaker, P. G.; Nibbering, N. M. M.; Vekey, K.; Drahos, L.; Heeren, R. M. Manipulating Internal Energy of
Protonated Biomolecules in Electrospray Ionization Fourier Transform Ion Cyclotron Resonance Mass Spectrometry. J. Mass Spectrom. 2003, 38, 597-606.

19. Collette, C.; Drahos, L.; Pauw, E. D.; Vékey, K. Comparison of the Internal Energy Distributions of Ions Produced by Different Electrospray Sources. Rapid Commun. Mass Spectrom. 1998, 12, 1673-1678.

20. Kertesz, T. M.; Hall, L. H.; Hill, D. W.; Grant, D. F. CE50: Quantifying Collision Induced Dissociation Energy for Small Molecule Characterization and Identification. J. Am. Soc. Mass Spectrom. 2009, 20, 17591767.

21. Memboeuf, A.; Nasioudis, A.; Indelicato, S.; Pollreisz, F.; Kuki, Á; Kéki, S.; van den Brink, O. F.; Vékey, K.; Drahos, L. Size Effect on Fragmentation in Tandem Mass Spectrometry. Anal. Chem. 2010, 82, 2294-2302.

22. Sztáray, J.; Memboeuf, A.; Drahos, L.; Vékey, K. Leucine Enkephalin-a Mass Spectrometry Standard. Mass Spectrom. Rev. 2010; in press. 